\title{
Studies and Suggestions on Prewriting Activities
}

\author{
Shigao Zheng (Corresponding author) \\ Foreign Languages School, China University of Petroleum, Beijing \\ 18 Fuxue Road, Changping District, Beijing 102249, China \\ Tel: 86-10-8973-3282Ｅ-mail: jeffzheng@cup.edu.cn \\ Weiping DAI \\ Foreign Languages School, China University of Petroleum, Beijing \\ 18 Fuxue Road, Changping District, Beijing 102249, China \\ Tel: 86-10-8973-3282Ｅ-mail: dwping@cup.edu.cn
}

Received: December 22, 2011

Accepted: January 12, 2012 Published: March 1, 2012

doi:10.5539/hes.v2n1p79

URL: http://dx.doi.org/10.5539/hes.v2n1p79

\begin{abstract}
This paper studies and suggests the need for writing instruction by which students can experience writing as a creative process in exploring and communicating meaning. The prewriting activities generate ideas which can encourage a free flow of thoughts and help students discover both what they want to say and how to say it on paper. Through the activation of the formal schema, students can understand how to organize the material according to the requirements of the writing task and the general structure of the English composition. The authors choose a writing task in College English as an example to show the teaching procedure in the prewriting process. Through the instruction of the writing task on an argumentation, the authors summarize the essential steps of the teaching of English prewriting activities.
\end{abstract}

Keywords: Prewriting activities, College English writing, Teaching

\section{Introduction}

English has become a sure access to information of all sorts and an indispensable means of international communication. The emphasis on EFL teaching has also shifted from purely structured competence to communicative competence - from the ability to merely manipulate the linguistic structure correctly to the ability to use the language to communicate in both spoken and written forms.

These changes have altered people's thinking of EFL writing. It's no longer just a means to test or reinforce what a foreign language learner has learned, but a necessary tool for the learner to communicate with people in the real world. Therefore, the teaching of EFL writing has also seen some dramatic changes during recent years, and more attention and researches have focused on the enrichment of theories on writing. There are several effective approaches to teaching writing, for instances: the product approach, the process approach, the genre approach, and the genre process approach. Among them, the process approach is the most widely accepted one in many foreign countries and has proved to be more effective in improving learner's writing abilities.

In the process theorists' point of view, well-written essays are the fruits of a long, laborious, intensely personal process of thinking, verbal communication, and an interactive, socio-cognitive behavior. Meaning is not thought up and then written down. The act of writing is an act of thought. Language and thought are inseparable. They are processes in which writers must address questions, ranging from "What do I write about?" to "Who is my audience?" to "How do I structure my essay?" to "What sort of language and voice should I use?" Murray (1993: 346) holds that writing should be treated as a process, i.e., "a series of steps or stages an author goes through to develop a piece of writing." Tribble (1996: 160) defines the process approach as "an approach to the teaching of writing which stresses the creativity of the individual writer, and which pays attention to the development of good writing practices rather than the imitation of models". Thus, the focus shifts from the final product itself to the different stages the writer goes through in order to create this product by breaking down the task as a whole into its constituent parts. Writing becomes less daunting and more manageable to the EFL students.

The principal features of the process approach are (Doust, C., 1986): (1) A view of writing as a recursive process 
that can be taught; (2) An emphasis on writing as a way of learning as well as communicating; (3) A willingness to draw on other disciplines, notably cognitive psychology; (4) The incorporation of a context, a view that writing includes a sense of audience, purpose, and occasion; (5) A procedure for feedback that encourages the instructor to intervene during the process (formative evaluation), and so aid the student to improve his/her first or initial drafts; (6) A method of evaluation that determines how well a written product adapts the goals of the writer to the needs of the reader as audience; (7) The principle that writing teachers should be people who write.

Writing is often called a recursive process. This means that many steps to writing an effective paper do not necessarily follow neatly one after the other. In fact, you will find yourself repeating the same step a number of different times, in a number of different places, as you write a paper. Generally speaking, the writing processes consist of prewriting, writing and revising (Flower \& Hayes, 1981; Murray, 1980; Anderson, 1991; Hall, 1990).

The prewriting process involves anything you do to help yourself decide what your central idea is or those details, examples, reasons, or content that should be covered. Free writing, brainstorming, and clustering are types of prewriting. Obviously, you can pre-write at any time in the writing process. Whenever you want to think up new material, simply stop what you are doing and start using one of the techniques you will study in this paper.

The writing process involves the actual writing out of a draft. Unfortunately, many people try to start their writing without sufficient prewriting. As you may know from firsthand experience, trying to start out this way usually leads directly to a good case of writer's block. During this stage of the writing process, you should be ready to do more prewriting whenever you hit a snag or can not think of what to writer next.

\section{Prewriting Activities}

Teachers can use various methods in teaching English writing. However, there might be a question: how to appropriately apply these methods in practice. Hence, the authors of the present paper choose the writing task "Coping with an Educational Problem" in Book One of College English published in China as the teaching material to show how to activate students' content schemata and formal schemata. This part is "Theme related Language Learning Tasks", which includes three tasks: Mock Debate, Essay Writing, and Follow-up Work.

\subsection{Brainstorming}

The first task is Mock debate, which serves as part of the prewriting activities. The topic of the debate is Effects of the Increasing Use of Computers in Schools. The requirement goes like this: Students today are making more and more frequent use of computers. Does the increasing use of computers do good or harm to them? Some hold that it benefits the students in many ways, but others argue that it causes problems. As a result, a debate is called for.

The textbook provides three steps for the debate:

\section{Step 1 Form teams}

Make teams of four people. Half of the teams will be Affirmative Teams and half of the teams will be Negative Teams.

\section{Step 2 Have a pre-debate discussion}

Prepare your arguments and supporting facts by brainstorming together.

Step 3 Carry on the debate

Now the debate begins. The teams face each other. The Affirmative Team states its first reason and support. The Negative Team returns a refutation. The Affirmative Team must then respond to the Negative Team's refutation. The debate continues until one side can not respond. The last team to give a response is the winner.

From the above requirements, we know that brainstorming is required in this prewriting activity. This debate is to collect information for the writing task. So, what is important in this activity is to brainstorm. The teacher can first instruct the students to take this activity to get necessary vocabulary and information.

When students are working in groups, the teacher should not sit and wait for the answer. Instead, he/she should walk around and join in the brainstorming activity. After three or four minutes, the teacher can ask two or three groups in each Team (Affirmative Team and Negative Team) to report their findings. Because the brainstorming activity only focuses on the quantity, not the quality, so any findings of the students should be accepted and encouraged. The teacher can decide which findings are useful in the following activities.

For example, the groups in the Affirmative Team can list the following findings:

1) The application of the computer and multimedia in the class can better stimulate students' interests, and the traditional way of teaching with a textbook and a piece of chalk can no longer fit the current situation. 
2) The computer makes the office work easier, because it has a large storage and can save time in editing work.

3) The computer gives students easy access to a wealth of reference material. Hence, students can easily find out the material for their papers.

4) The computer offers some interesting games for killing time, which, to some extent, enriches student's school life.

5) The computer can process the information very quickly, thus, it can be used in many circumstances, e.g. in the shopping center, the office, and so on.

6) The computer connected with Internet can help people exchange information and material very conveniently.

7) The Internet offers one with the opportunities to communicate with people all over the world by chatting through MSN etc. or by sending E-mails.

8) Some computer programs are designed to help students improve their learning.

9) The students of art can turn to the computer for help when drawing.

10) The use of computers greatly enlightens the student's life, because students can watch films, or listen to the music at will.

11) The use of computers reduces the demand of chalks, which can contribute somehow to the environment protection.

12) The computer shortens the teacher's time spent in preparing the class; meanwhile, it greatly enriches the information the teacher provides in classroom.

13) The wide use of computers provides many posts for the students to seek after graduation.

The groups in the Negative Team might present the following findings:

1) Playing video games wastes too much time and money on the part of the students.

2) Using the computer for a long time may hurt the user's eyesight, wrist, back, and so on.

3) Viewing of undesirable material on the Internet may result in some unhealthy thoughts and actions.

4) Easy access to the reference information encourages the plagiarism among some researchers and students.

5) The used computers might be purchased again by the students because of the low price, which may pose many potential dangers.

6) The use of computers brings more pressure on the electronic supply.

7) Chatting online attracts many students, which may lead to spending less time studying, or even doing something evil, or being cheated by some people with evil aims.

8) The use of computers greatly shortens the student's time spent in learning some difficult tasks, because they are no longer interested in these difficult tasks.

9) The wide use of computers hinders students from communicating person to person, which may result in their lack of practice in terms of communication.

10) The complete dependence on the computer in classroom leaves the students tired all through the class, because with the aid of the computer, the teaching pace will be faster than the traditional way of teaching.

11) The students may be so addicted to the computer that they are no longer interested in such activities as physical exercises, and visiting friends.

12) The use of computers increases the requirements of students' English level, which is the weak point of many non-English majors.

13) The wide use of computers makes the student pay less attention to their handwriting, thus, students' handwriting and their Chinese language show a decreasing tendency. So, some researchers propose and urge the students to learn Chinese in College.

14) The computer provides many supporting materials for students to learn after class, hence, some students lose interests in classroom activities, which increases the difficulty of the teaching.

The brainstorming activity in classroom should be carefully controlled. The teacher should stop their discussion when most of the students have finished their brainstorming discussion. Otherwise, the time in class will be wasted in chatting or other meaningless activities. Besides, when presenting the findings, the teacher should type or write 
out the key words only instead of the complete sentence. Last but not the least, the teacher should add something of his/her own on to students' findings in order to encourage students' creation.

\subsection{Semantic Mapping}

Brainstorming focuses on the quantity itself, not the quality, and it provides a lot of material to be selectively used, but whether they are useful or not should be immediately determined. Hence, the next step is required to polish the findings in brainstorming. Here, the authors choose semantic mapping, which helps decide whether the information is in correspondence with the theme of the writing task.

Let's first look at the requirements of the writing task:

Drawing on the opinions of both sides in the debate about the question, write an essay entitled "The use of computers in schools" according to the following outline:

1) In what way you think the increasing use of computers is of benefit to students.

2) In what way you think the increasing use of computers is bad for students.

3) Your conclusion.

From the requirements provided, we know the important points to be covered in the coming writing task. The composition consists of three paragraphs according to the outline. The first paragraph should cover the benefits of the increasing use of computers in school, the second paragraph the harm of the increasing use of computers in school, and the last paragraph is the writer's opinion. Therefore, what we should do next is to choose from the above findings of brainstorming activities the most related and the most representative information. For the benefits, the teacher can instruct students to choose from the findings of the Affirmative Team; for the harm, the student can choose from the findings of the Negative Team.

The next step is to decide which is representative. The principle is to find out an opinion that is comprehensive enough to be a sub-branch of the given topic. The given topic should be carefully divided into several related sub-topics, among which the dividing line should not overlap, and some points should be omitted. Hence, the teacher can discuss with the class to work out an outline of the composition as those listed in the following table 1 .

Insert Table 1 in here.

From the above table, students can get a general idea of what to write in the immediate writing task. Then, the teacher can instruct students to choose from the findings they and their "rivals" have got in the previous brainstorming activities to fill in the above table.

For example, benefits to teaching may include those listed in the following:

1) The application of the computer and multimedia in the class can better stimulate students' interests, and the traditional way of teaching with a textbook and a piece of chalk can no longer fit the current situation.

2) The computer shortens the teacher's time spent in preparing the class; meanwhile, it greatly enriches the information the teacher provides in classroom.

Benefits to learning may include those listed in the following:

1) The computer gives students easy access to a wealth of reference material. Hence, students can easily find out the material for their papers.

2) Some computer programs are designed to help students improve their learning.

Benefits to students' life may include those listed in the following:

1) The computer offers some interesting games for killing time, which, to some extent, enriches student's school life.

2) The use of computers greatly enlightens the student's life, because students can watch films, or listen to the music at will.

Harm to teaching can be:

1) The computer provides many supporting materials for students to learn after class, hence, some students lose interests in classroom, which increases the difficulty of the teaching.

Harm to learning can be:

1) Easy access to the reference information encourages the plagiarism among some researchers and students.

2) The complete dependence on the computer in classroom leaves the students tired all through the class, 
because with the aid of the computer, the teaching pace will be faster than the traditional way of teaching. Harm to students can be:

1) Playing video games wastes too much time and money of the students.

2) Using the computer for a long time may hurt the user's health, for examples: the eyesight, the wrist, the back, and so on.

The conclusion should be the writer's attitude towards the use of computers in schools. Therefore, the writer should state clearly whether they are for or against it. For example, "The advantages clearly outweigh the disadvantages, so we should encourage the use of computers in schools"; "Since the computer can bring so many harms to the students, we should gradually reduce the use of computers in schools", and so on.

\subsection{Genre Modeling}

After finishing the above two activities, students would have got enough material for the coming writing task. However, having the material only is far from enough. Like building a house, the chosen material in the writing activities is the brick and the cement. What students should do next is to reasonably organize the chosen material into a coherent composition, just like the way workers build the house. Next, the teacher should show some genre models and explain the paragraph development and coherence to help students understand how to organize the composition.

\section{Model Composition:}

\section{The Use of Computers in Schools}

There are numerous benefits that flow from the use of computers in schools. Interest in a subject can be stimulated by sound and visual illustrations more than by "chalk-and-talk" alone and students are given easy access to a wealth of reference material. Internet access offers the chance to communicate with other students around the world. Programmed learning tailored to the speed of individual students can be adopted. Computer skills such as programming can be developed.

There is, however, a negative side. There is the danger that computers encourage "cut-and-paste" copying without a real understanding of what is being said. Also, for many purposes traditional teacher-centered classrooms remain more effective than time spent working alone. And, of course, computers always offer the temptation to play games rather than get down to difficult learning tasks.

On balance, however, the advantages clearly outweigh the disadvantages.

The writing task "The use of computers in schools" requires an argumentation. The teacher should firstly explain the general structure of the argumentation. A typical argumentation includes the opinion, the evidence, and the conclusion. Generally speaking, the opinion should be stated clearly firstly in the student composition, followed by supporting evidences or sub-opinions, and the conclusion or the writer's attitude comes as the ending of the composition. The schematic structure of an argumentation goes like:

No. 1: opinion + supporting evidence $1+$ supporting evidence $2+\ldots+$ supporting evidence $n$. + conclusion; or

No. 2: opinion + sub-opinion $1+$ supporting evidence + sub-opinion $2+$ supporting evidence $+\ldots+$ sub-opinion $3+$ supporting evidence + conclusion.

For example, the writing task in the CET Band 4 administered in June, 2007 by the Ministry of Education to Non-English major students nationwide required the examinees to write a composition on the topic "Is a Test of Spoken English Necessary?" The first sentence has already been written for the examinees. They should write at least 100 words, and base their composition on the outline given below:

1) Many people argue that it is necessary to hold a Spoken English test because......

2) But some people hold different opinion as to the Spoken English test......

3) Your opinion

\section{Model Composition:}

\section{Is a Test of Spoken English Necessary?}

A host of people think it is necessary to hold spoken English test. They think if one wants to master English well, he/she has to speak fluent and idiomatic English. Firstly, such a test can motivate students to plunge into learning spoken English. Secondly, China is a competing society. Perhaps you will beat your rival to secure the job which you are satisfied with by speaking fluent English. Lastly, China has been experiencing reform and 
opening-up. Many foreigners have come to China. If you want to communicate with them, you have to speak fluent English. All these points are indispensable to holding spoken English test.

Some people, however, take a different attitude: Spoken English test is regarded as being unnecessary. For one thing, they think China does not have a good language environment in which to practice spoken English. For another, in daily life, most of us have a touch with Chinese. It is unnecessary for us to communicate with each other in English.

As far as I am concerned, I am in favor of holding spoken English test which will benefit students forever. If you can speak English fluently, you will be proud of yourself. So I am determined to improve my spoken English and make good use of every opportunity to practice my spoken English.

\section{Model Composition:}

\section{Should university students go in for business?}

A few sophomores and juniors are reported to have opened six small shops near their university in order to get prepared for the future. According to a newspaper, their teachers and classmates hold different opinions about this phenomenon. Some agree with this practice, while others hold a negative view. Personally I am in favor of this practice.

I think it is good for university students to go in for business. Firstly, the students' business experience will help them adapt better to the society after graduation. As colleges and universities nationwide enlarge enrollment and more graduates are produced each year, the competition in the job market has become even more throat-cutting. By going for business, university students can accumulate some experiences, improve their ability to handle interpersonal relationship, learn how to cooperate with people, and thus getting better prepared for the future, and becoming more competitive in the job market.

Besides, running shops may bring some profit for college students, and it is especially so for needy students. College education is no longer free now. Therefore, if they can earn some money from running the shops, they will help to relieve the burden of their families. Thirdly, if college students can apply their professional knowledge, management and accounting skills, for example, to running the shops, it would be the best way for them to practice what has been learned in the classroom.

There are disadvantages to the practice, however. For example, running shops might occupy too much of the students' time and energy, which should otherwise be devoted to their academic study. But, taken as a whole, I believe the advantages far outweigh the disadvantages.

Let's look back at the writing task of the Text "The use of computers in schools". It requires students to state the effects of the increasing use of computers among students in schools, and the principal logic development involved in this writing task is cause and effect. The increasing use of computers in schools is the cause. The writer should list the effect, i.e. the benefit and the harm to students, of the increasing use of computers.

Cause and effect analysis is an important analytical skill in essay writing. When writing a cause-and-effect paper, instructors should bear in mind the following points:

1) Sound reasoning or logic: when discussing causes and effects, one should make sure one's analysis is logical. One must not take it for granted that event A causes event B simply because A precedes B. In other words, one must explain clearly what really brings about a particular result.

2) Possible shift in order: in cause and effect writing, it seems convenient to state the effect first and then analyze the cause. The reverse order, however, is to be preferred when one cause leads to a number of effects (Li Yinhua, 2001:252).

Therefore, the teacher, firstly, should instruct students to get familiar with these writing strategies which can help them know what to write and how to organize the framework. From the analysis of the given writing task and the cause and effect writing strategy, we can see the second point discussed above suits the given writing task, that is, the reverse order should be adopted in this writing task. So, the cause should be stated firstly, and then a number of effects, including the benefits and the harms. In expressing the cause and effect, some phrases or words like "seeing that, considering that, now that, in that, since, as, for, etc" may be needed, so the teacher should let students get familiar with them in advance. All in all, the teacher should make students aware of the logic development of the given writing task in prewriting activities. In explaining one cause and a number of effects, the teacher can cite the following model paper to explain how to develop the logic relationship. 


\section{Model Composition:}

(Cause) Cigarette smoke contains nicotine, several caner-producing or irritating substances and carbon monoxide gas. (Effect 1) Damage to the lining of the bronchial tubes is much more common among cigarette smokers than non-smokers, even when there is no obvious disease. Some of these changes are considered to be pre-cancerous. (Effect 2) Lung function is generally reduced among cigarette smokers. Cigarette smoking is a greater hazard than other factors - such as community air pollution - in the causation of lung cancer and chronic bronchitis.

This paragraph adopts the logic order of "cause - a number of effects - stating the theme", and this way of writing highlights the harm of cigarette smoking, which is better than stating the effect first, then analyzing causes. Because the cause is obvious, what should be emphasized is the effect of the cause - cigarette smoking, and then warning to the cigarette smoking or banning of it can be reasonably followed.

As the main idea of each paragraph has been given, the writer can easily figure out what to write in each paragraph. Thus, in the next step, the teacher should instruct students to connect these paragraphs. Paragraph One should be the benefit of the increasing use of computers in schools; Paragraph Two the harm of it. The writer should choose some conjunctive words to show the contrast between them instead of listing the benefits and the harms alone without mentioning their relationship. The writer can choose some phrases or sentences like: As the saying goes; A coin has two sides, so does the use of computers; There is, however, a negative side; Let's take a different respective; Although (Even though) there are so many benefits of the increasing use of computers in schools, we can not ignore the harms it brings; and so on.

For the last paragraph, a conclusion is needed, which should be introduced by some of the words or phrases like "in summary, to sum up, in conclusion, in short, in brief, on the whole, all in all, as has been noted, thus, hence, eventually, from this point of view". The conclusion consists of closing statement and concluding sentence. The former makes the reader aware of the coming ending of the composition; the latter states the writer's further attitude after the above discussion, and provides a general conclusion. There are many ways of writing the concluding sentence, for example, by providing more general conclusion, or by making suggestions, or by proposing some solutions to the above discussed problem, or by predicting or warning, etc.

\subsection{Outlining the Composition}

After the teacher has analyzed the genre model and paragraph development in detail, students can now draw an outline of their composition. The outline can be a further selection of the semantic map. In the semantic mapping activity, some materials are chosen from the brainstorming activity. These chosen materials may be further selected in order to make it fit the theme of the given topic.

In the above discussion of semantic mapping, both the benefit and the harm have been analyzed from three aspects: the teacher, the student, and the student's life. Each aspect has found two or three findings. If we put all of them in the composition, they will make the composition too verbose. Hence, we'd better select the most representative one for each aspect to outline the composition. In this way, the composition would be coherent, and comprehensive.

For examples:

Benefits to teaching:

The application of the computer and multimedia in the class can better stimulate students' interests, and the traditional way of teaching with a textbook and a piece of chalk can no longer fit the current situation.

Benefits to learning:

The computer gives students easy access to a wealth of reference material. Hence, students can easily find out the material for their papers.

Benefits to students:

The use of computers greatly enlightens the student's life, because students can watch films, or listen to the music at will.

Harm to teaching:

The computer provides many supporting materials for students to learn after class, hence, some students lose interests in classroom, which increases the difficulty of the teaching.

Harm to learning:

Easy access to the reference information encourages the plagiarism among some researchers and students. 
Harm to students:

Playing video games wastes too much time and money of the students, and hurts the user's eyesight, wrist, back, etc.

The conclusion can be:

The advantages clearly outweigh the disadvantages, so we should encourage the use of computers in schools".

Hence, these seven sentences make the whole composition which lists advantages and disadvantages reasonably from three different aspects, and which clearly states the writer's attitude towards the increasing use of computers in schools. What's more, students can grasp the writing strategy for the argumentation, especially the cause and effect argumentative composition, which is the most important in the teacher's respective.

To sum up, the teaching procedure of the prewriting process can be:

Step 1: conducting the brainstorming activity to collect materials for the given topic;

Step 2: relying on the semantic mapping activity to initially select the required material from the above findings, which will deal with the issue of what to write;

Step 3: introducing the genre models and paragraph development to help students understand how to organize the chosen material;

Step 4: performing the outlining activity to further modify the chosen material and form the framework of the composition and provide the foundation for the following writing processes.

The above four steps of the prewriting process can be altered in order to fit other types of writing. Because this teaching model is only based on an argumentation writing task, it might not fit the other types of composition. However, the general teaching steps are similar, and therefore, we may say this teaching model might be useful in most prewriting processes. Whether it is efficient and effective requires further empirical studies.

\section{Conclusion}

In the prewriting process, what is important is to activate students' schematic knowledge, both content and formal. The prewriting stage requires more activities on the activation of the schematic knowledge than the other two stages: the writing stage and the post-writing stage (revising and editing). In prewriting process, the teacher should consciously activate students' content and formal schemata. In terms of content schemata, several methods can be adopted, such as semantic mapping, brainstorming, class discussion, etc. The content schema can provide the one with the material on which one might base his/her writing work. Meanwhile, formal schemata should be activated by introducing genre models, paragraph development and coherent devices. The formal schema can direct the students to organize the chosen material into a coherent composition.

In order to show how the content schema and the formal schema are activated, the authors chooses a writing task in College English as an example to show the teaching procedure of the application of Schema theory in the prewriting process. This paper proposes four steps in the prewriting process. This teaching model might be altered in order to fit all the types of writing, because this model is only based on an argumentative writing task. Though the exemplar can make things clear, whether it will function well in the teaching practice still needs to be further tested by empirical studies in the future.

\section{References}

Anderson, J. W. (1991). A comparison of Arab and American conceptions of effective persuasion. In L. A. Samover, \& R. E. Porter (eds.), Intercultural communication: A reader. Belmont, CA: Wadworth.

Atwell, N. (1981). In the middle: Writing, reading, and learning with adolescents. Portsmouth, NH: Heinemann.

Brown, H. D. (1994). Teaching by Principles: An Interactive approach to Language Pedagogy. Prentice Hall Regents.

Doust, C. (1986). Teaching writing as a process. Sacra-mento, Calif: California State Department of Education.

Flower, L., \& Hayes, J. R. (1981). A cognitive process theory of writing. College Composition and communication, (32): 365-387. http://dx.doi.org/10.2307/356600

Graves, D. H. (1983). Writing: teachers and children at work. London and Portsmouth, NH: Heinemann.

Hyland, Ken. (2005). Teaching and Researching Writing. Beijing: Foreign Language Teaching and Research Press.

Li, Y.H. (2001). College English. Shanghai: Shanghai Foreign Language Education Press.

Murray, D. M. (1980). Writing as a process: How writing finds its own meaning. In T. R. Donovan, \& B. W. McClelland (eds.). Eight approaches to teaching composition. Urbana, Illinois: National Council of Teachers of 
English, 3-20

Murray, D. M. (1993). Assumptions. In Cleary, L.M \& Linn, M.D. (eds.) Linguistics for Teachers. NY: McGraw-Hill, 337-339

Nunan, D. (2001). Second Language Teaching. Beijing: Foreign Language Teaching and Research Press.

Qi, S.H. (2000). Western Writing Theories, Pedagogies, and Practices. Shanghai: Shanghai Foreign Language Education Press.

Tribble, C. (1996). Writing. Oxford: Oxford University Press.

Wang, J.J. (2005). From Ideas to Text: A cognitive study of English writing processes. Jinan: Shandong University Press.

Widdowson, H. G. (1983). Learning Purpose and Language. Oxford: Oxford University Press.

$\mathrm{Wu}$, J., \& Zhang, Z. X. (2005). A study of the feasibility of prewriting in teaching composition. Foreign Language Teaching and Research, (5): 213-218

\section{Authors}

Shi-gao Zheng, male, born in 1976, lecturer of English with the School of Foreign Languages, China University of Petroleum. Attained M.A. in ELT in 2005. Specialize in English Language Teaching. Over 20 papers and books published.

Wei-ping DAI, male, born in 1956, professor of English with the School of Foreign Languages, China University of Petroleum. Attained M.A. in ELT from Essex University, UK in 1996. Specialize in English Language Teaching. Over 100 papers and books published.

Table 1.

\begin{tabular}{|l|l|l|}
\hline \multicolumn{2}{|l|}{ The use of computers in schools } \\
\hline Benefits & Harm & Conclusion \\
\hline 1.to teaching & 1.to teaching & The attitude: for or against the use of \\
2.to learning & 2.to learning & computers \\
3.to students & 3.to students & \\
\hline
\end{tabular}

